\title{
A Comparison of High-Frequency Oscillation Superimposed onto Backup Mechanical Ventilation and Conventional Mechanical Ventilation on the Distribution of Exogenous Surfactant in Premature Lambs ${ }^{1}$
}

\author{
FRANS J. WAITHER, IRENE M. KUIPERS, CORRIE E. M. GIDDING. DIRK WIIIIBRANI). \\ RUルI) T. F. BU(HHOI.TZ. AND FDOUARI) M. BFVERS

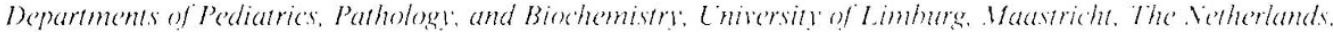 \\ and Department of Pediatrics. Los Angeles County-Liversity of Southern Califormia Bedical ('enter. \\ I.os Angeles. (alifornia $9(0) 33$
}

\begin{abstract}
ABSTRACI. Twenty-six premature lambs were treated by tracheal instillation of $\left.\right|^{14} \mathrm{Cllabeled}$ natural sheep surfactant before the onset of breathing or after the establishment of respiratory distress syndrome $30 \mathrm{~min}$ after birth. Half of both groups were subsequently ventilated for $3 \mathrm{~h}$ with $100 \% \mathrm{O}_{2}$ by conventional mechanical ventilation (CMV) and half by high frequency oscillation superimposed onto backup mechanical ventilation $(\mathrm{HFOV})$. Mean airway pressure, arterial blood pressures, and heart rate were recorded continuously. Arterial blood gases and pH were obtained every $15 \mathrm{~min}$. After sacrifice, the distribution of radiolabeled surfactant was quantified and alveolar expansion was evaluated by morphometrics. At comparable oxygenation, mean airway pressures were significantly lower in the lambs treated with surfactant at birth (groups CMV$B$ and IIFOV-B) than in lambs on CMV and treated with surfactant during RDS (group CMV-R). Mean airway pressures in both groups of lambs on HFOV (groups $\mathrm{IHF}(\mathrm{V}-\mathrm{B}$ and HFOV-R) were comparable at values lower than in group CMV-R and higher than in group CMV-B. The distribution of radiolabeled surfactant was more homogeneous in lambs treated at birth and not different for both types of ventilatory assistance. Morphometrics demonstrated significantly better expansion of the alveoli of lambs ventilated with IIFOV than of those on CMV, irrespective of the timing of surfactant administration. These results indicate that prophylactic surfactant administration at birth leads to a better distribution of surfactant than rescue treatment with surfactant after the establishment of respiratory distress syndrome and is not affected by a subsequent type of ventilatory assistance. Rescue treatment with surfactant and subsequent $\mathrm{HFOV}$ leads to better oxygenation and alveolar expansion at comparable mean airway pressures than rescue treatment followed by CMV. (Pediatr Res 22: 725-729, 1987)
\end{abstract}

\section{Abbreviations}

CMV, conventional mechanical ventilation $\mathrm{HFOV}$, high frequency oscillation ventilation

Received May 11, 1987: accepted August 11, 1987

Correspondence and reprint requests firans J Walther. M.D. Ph.D. Vewborn Division, Rm I919. Women's Hospital, IAC-USC Medical Center 1240 N. Mission Road, I os Angeles, (A 9()$) 33$

'Results presented in part at the Annual Meeting of the Society for Pediatric Rescarch. Anahcim. (A April 29, 1987.
MAP, mean airway pressure

$\mathrm{PaO}_{2}$, partial arterial oxygen pressure

$\mathrm{PaCO}_{2}$, partial arterial carbon dioxide pressure

PEEP, positive end-expiratory pressure

RDS, respiratory distress syndrome

$V I$, ventilatory index

VT, tidal volume

Tracheal instillation of exogenous surfactant into premature animals and infants with RDS induces a rapid improvement of pulmonary function. Giving surfactant at birth takes advantage of the lungs being filled with fluid. It allows for the mixing of surfactant with lung fluid and leads to an even distribution of surfactant as the lung fluid recedes (1). After birth. lung fluids diminish quickly and the distribution of exogenous surfactant after air breathing will be more uneven (1). This is in line with the observation that injecting surfactant into the fluid-filled airways of animals and infants before the initiation of breathing leads to a clinical response of longer duration than administration of a surfactant suspension after a period of air breathing (2-4).

However, the distribution of exogenous surfactant may not only depend on the timing of its instillation. but also on the type of ventilatory assistance used thereafter. Data on the influence of different modes of assisted ventilation on the ultimate distribution of exogenous surfactant in infants with respiratory distress syndrome are lacking. Several studies in adult rabbits with surfactant deficient lungs $(6-8)$ indicate that HFOV may be superior to CMV due to the absence of swings in end-tidal lung volume. We compared the effects of HFOV and CMV on the distribution of exogenous surfactant in premature lambs treated with radiolabeled surfactant before the onset of breathing or after a period of CMV because of RDS.

\section{METHODS}

Mechanical ventilation. HFOV was delivered at a frequency of $15 \mathrm{~Hz}$ and a tidal volume of $2 \mathrm{ml} / \mathrm{kg}$ using a HFOV-CMV system (8.9). HF()V was generated by an electric piston pump with a volume adjustable between 1 and $50 \mathrm{ml}$ and frequencies between 1 and $30 \mathrm{~Hz}$. The piston was connected with the upper part of the endotracheal tube by means of a noncompliant tube. It oscillated the gas flowing through the ventilator circuit without 
adding new gas. The oscillations were added on the CMV waveforms. CMV was administered with a constant-flow, time-cycled, pressure-limited ventilator (Amsterdam Infant Ventilator, MK 2, Hoek and Loos, Amsterdam, The Netherlands) delivering humidified and warmed oxygen. Ventilator settings were as follows: an initial peak inspiratory pressure of $25 \mathrm{~cm} \mathrm{H} \mathrm{H}_{2} \mathrm{O}$, a PEEP of $3 \mathrm{~cm} \mathrm{H} \mathrm{H}_{2} \mathrm{O}$, a rate of 40 breaths/min, an inspiratory time of $0.75 \mathrm{~s}$, and a $\mathrm{FiO}_{2}$ of 1.0. Subsequently, only peak inspiratory pressures were changed in an attempt to normalize $\mathrm{PaCO}_{2}$.

Surfactant. Natural surfactant was recovered by a series of centrifugation steps from the lung lavage of healthy adult sheep. The isolation procedure, phospholipid composition, protein content, and clinical activity of this surfactant have been reported (10). Uniformly labeled $\left[1-{ }^{14} \mathrm{C}\right]$ palmitate dipalmitoylphosphatidylcholine $(117 \mathrm{mCi} / \mathrm{mmol})$ was purchased from Amersham International (Buckinghamshire, England). The ${ }^{14} \mathrm{C}$ solution was dried under $\mathrm{N} 2$, suspended in distilled water by sonication (11) and added to the natural surfactant to a final concentration of 1 $\mu \mathrm{Ci}$ of $\left[1-{ }^{14} \mathrm{C}\right]$ palmitate dipalmitoylphosphatidylcholine and 180 $\mathrm{mg}$ of natural sheep surfactant lipid in $10 \mathrm{ml}$ of natural surfactant. Each lamb received $60 \mathrm{mg}$ of natural sheep surfactant lipid and $0.33 \mu \mathrm{Ci}$ of $\left[1-{ }^{14} \mathrm{C}\right]$ palmitate dipalmitoylphosphatidylcholine per $\mathrm{kg}$ body weight.

Lambs. All premature lambs were delivered at 126-132 days of gestation by cesarean section under general anesthesia of datemated Texel breed ewes carrying twins or triplets. The head and neck of each lamb was mobilized, and the midanterior neck exposed through a uterine incision. An uncuffed endotracheal tube (internal diameter $4 \mathrm{~mm}$ ) was inserted and tied into the trachea. A $10-\mathrm{ml}$ sample of fetal lung fluid was aspirated for phospholipid analysis. The endotracheal tube was occluded to prevent entrance of air to the lungs. A $5 \mathrm{Fr}$. polyethylene catheter was placed in a carotid artery and a 3.5 Fr. polyethylene catheter was placed into a jugular vein. An umbilical arterial blood sample was obtained for $\mathrm{pH}$ and blood gas analysis, the lamb was delivered, weighed, and mechanical ventilation was started. The lambs were paralyzed with $0.1 \mathrm{mg} / \mathrm{kg}$ of pancuronium bromide and received $10 \mathrm{mg} / \mathrm{kg}$ of phenobarbital sodium intravenously. The lambs were dried and placed on a heating mattress under an infant radiant heater and supplemental heat lamps. Rectal temperature was monitored and body temperature was maintained at $38-39^{\circ} \mathrm{C}$. Arterial blood gases and $\mathrm{pH}$ were sampled every 15 min and measured with an AVL-940 blood gas instrument. MAP was measured through a saline-filled polyethylene catheter with an internal diameter of $1 \mathrm{~mm}$, which was not connected to the endotracheal tube. It extended $2 \mathrm{~cm}$ beyond the distal tip of the endotracheal tube and had, in addition to the central lumen, two intramural lumens close to its tip. The airway catheter was connected to a pressure transducer (Gould Inc., Oxnard, CA). The signal was amplified and displayed continuously on an eight-channel Schwarzer polygraph calibrated to the high range using a mercury manometer and zeroed to atmospheric pressure. Heart rate and arterial blood pressures were recorded continously on the polygraph. Each lamb received $10 \%$ dextrose through the venous catheter at a rate of $100 \mathrm{ml} /$ $\mathrm{kg} / 24 \mathrm{~h}$.

Thirteen lambs received radiolabeled surfactant by tracheal instillation at birth. Six lambs (group CMV-B) were subsequently ventilated with CMV and seven (group HFOV-B) with HFOV. Thirteen lambs were supported on CMV and did not receive radiolabeled surfactant until $30 \mathrm{~min}$ after birth. At treatment these lambs were all in respiratory failure as defined by elevated $\mathrm{PaCO}_{2}$ levels and low $\mathrm{pH}$ values on at least two blood gas samples. Seven of these lambs (group CMV-R) were continued on CMV and six (group HFOV-R) were switched over to the HFOV after instillation of surfactant. This led to the formation of four study groups. HFOV and CMV were alternately assigned to the first, second, or third born lamb of each twin or triplet. Three $\mathrm{h}$ after the tracheal instillation of radiolabeled surfactant, all lambs were sacrificed by a lethal pentobarbital overdose and subsequent exsanguination. A few minutes before sacrifice inadvertent PEEP was determined in the lambs on HFOV by clamping the endotracheal tube at end-expiration for $5 \mathrm{~s}$. This clamping procedure was repeated three times and the values were averaged to estimate inadvertent PEEP.

Processing of lungs. After sacrifice, the lungs were removed intact and weighed while still attached to the endotracheal tube at $15 \mathrm{~cm} \mathrm{H}_{2} \mathrm{O}$ distending pressure. The lungs were divided into 65 pieces with a weight of about $200 \mathrm{mg}$. Sixty biopsies, i.e. five superficial and five central biopsies from each of the upper, middle, and lower lobes, were used for estimation of the amount of radiolabeled surfactant. The superior and inferior right middle lobes were counted as one lobe. Five horizontal sections of each of the upper and lower lobes and of one of the right middle lobes were used for morphometrics. The tissue samples for surfactant quantitation were weighed, catalogued as to location, mixed with $0.5 \mathrm{~N}$ quaternary ammonium hydroxide in toluene, and placed in a shaking bath at $37^{\circ} \mathrm{C}$ for $36-48 \mathrm{~h}$ to obtain complete solubilization. After addition of Biofluor (DuPont, Boston, MA), the amount of radioactive surfactant was quantified. The biopsies for morphometrics (12) were immediately fixed in a 15:1:4 v/v mixture of alcohol $100 \%$, glacial acetic acid, and formaldehyde $40 \%$, stored overnight at room temperature, routinely paraffine embedded, cut in 4- $\mu \mathrm{m}$ sections, mounted on slides, and stained with hematoxylin and eosin. Each microscopic section was subsequently magnified 250 times under a Zeiss microscope and displayed with a Hitachi FP-10 videocamera on a monitor connected to a digitizer tablet. Using a manually operated cursor and retaining appropriate identification, the outline of each alveolus in a standard surface, encompassing at least 75 alveoli, was entered into a MOP Videoplan computer. Surface calculations (in $\mu \mathrm{m}^{2}$ ) for the digitized alveoli were made using methods similar to those of Cook et al. (13).

Data analysis and presentation. The number of radioactive counts, corrected for quenching, per piece of lung for each lamb was obtained and corrected for weight (dpm/g wet tissue). The values were then divided by the mean value for the lungs of that lamb to normalize the numbers. These ratios were turned into histograms with interval widths of $10 \%$ about the mean value of 1.0. All pieces having a normalized value $<0.15$ or $>1.85$ times the mean were grouped at the extremes of the distribution intervals (1).

All values are expressed as mean \pm SD unless otherwise indicated. Comparisons between groups were analyzed with Student's two-tailed $t$ test or $\chi^{2}$ test.

\section{RESULTS}

The lambs weighed $3.0 \pm 0.8 \mathrm{~kg}$ and were delivered at a gestational age of $130.5 \pm 1.3$ days. Arterial umbilical blood gases for the 26 lambs were $\mathrm{pH}, 7.29 \pm 0.05 ; \mathrm{PaO}_{2}, 27 \pm 8 \mathrm{~mm}$ $\mathrm{Hg}$; and $\mathrm{PaCO}_{2}, 48 \pm 8 \mathrm{~mm} \mathrm{Hg}$. Mean wet weight of the lungs was $103 \pm 22 \mathrm{~g}$. The lambs in the four groups were similar in terms of weight, gestational age, number of first-, second-, and third-born lambs, arterial umbilical blood gas and $\mathrm{pH}$ values, and wet weight of the lungs.

Figure 1 shows the $\mathrm{PaO}_{2}, \mathrm{PaCO}_{2}, \mathrm{pH}$, and MAP values of the lambs treated with radiolabeled surfactant at birth (groups CMV$\mathrm{B}$ and HFOV-B). Figure 2 presents these data for the lambs treated with surfactant after the establishment of RDS at $30 \mathrm{~min}$ of age (groups CMV-R and HFOV-R). The mean VI (VI = $\mathrm{PaO}_{2} / \mathrm{MAP} \times \mathrm{FiO}_{2}$ ) of group CMV-B was consistently higher during the experimental period than that of group CMV-R. At the end of the experiment, $3 \mathrm{~h}$ after the administration of radiolabeled surfactant, the mean VI was four times higher in the CMV-B group than in the CMV-R group $(29.4 \pm 21.2$ versus $7.5 \pm 3.3 \mathrm{~mm} \mathrm{Hg} / \mathrm{cm} \mathrm{H}_{2} \mathrm{O}, p<0.05$ ), indicating lower MAPs at comparable $\mathrm{PaO}_{2}$ in the lambs on CMV which were treated at birth. Lambs from group HFOV-B had a higher mean VI than lambs from group CMV-R $(14.5 \pm 7.9$ versus $7.5 \pm 3.3 \mathrm{~mm} \mathrm{Hg}$ / 


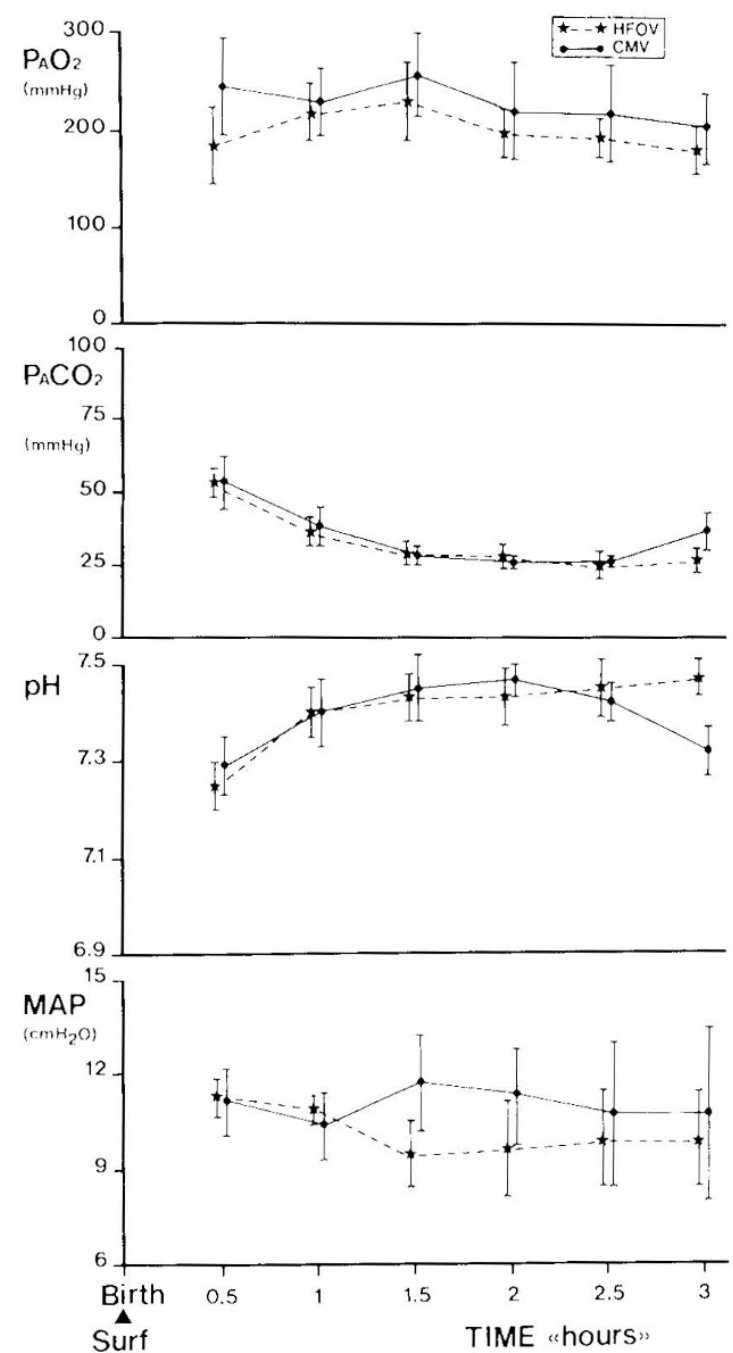

Fig. 1. Mean $( \pm \mathrm{SI})$ ) values of the $\mathrm{PaO}_{2}, \mathrm{PaCO}_{2}, \mathrm{pH}$, and $\mathrm{M} \wedge \mathrm{P}$ of the lambs treated with radiolabeled surfactant at birth (groups ( MV-B and HFOV-B).

$\left.\mathrm{cm} \mathrm{H}_{2}\right), p<0 .(05)$. Although the mean VI of the CMV-B group was twice as high as in the HFOV-B group at 2 and $3 \mathrm{~h}$ after birth, the difference was not statistically significant. Groups HFOV-B and HFOV-R had about equal VIs throughout the experimental period ( $14.5 \pm 8.0$ versus $14.9 \pm 10.1 \mathrm{~mm} \mathrm{Hg} / \mathrm{cm}$ $\mathrm{H}_{2} \mathrm{O} 3 \mathrm{~h}$ after surfactant administration). This indicates that MAPs necessary to obtain comparable oxygenation during HFOV were lower than those used for the CMV-R group but equal to or higher than those for the CMV-B group. Minimal MAPs were lower in the HFO-B group than in the HFO-R group $\left(5.92 \pm 1.74\right.$ versus $\left.8.33 \pm 0.72 \mathrm{~cm} \mathrm{H}_{2} \mathrm{O} . p<0.02\right)$ and lower in the CMV-B group than in the CMV-R group $(6.27 \pm 1.39$ versus $8.79 \pm 0.70 \mathrm{~cm} \mathrm{H}_{2} \mathrm{O}, p<(0.01)$. The differences between the HFO-B and CMV-B and between the HFO-R and CMV-R groups were not statistically significant.

Figure 3 shows the distribution of radioactive labeled surfactant in the four groups. The pieces of lung for the lambs treated after a period of ventilation were distributed in such a way that only $23.8 \%$ of the pieces in the HFOV-R group and $28 \%$ of the pieces in the CMV-R group received amounts of surfactant per $\mathrm{g}$ tissue within $\pm 25 \%$ of the mean. Distribution of surfactant in lambs treated at birth was more homogeneous with $45.9 \%$ of pieces in the HF()V-B group and $41.3 \%$ in the CMV-B group within $\pm 25 \%$ of the mean. The differences between the CMV$\mathrm{B}$ and $\mathrm{CMV}-\mathrm{R}$ groups $\left(\chi^{2}=12.769 ., p<0.001\right)$ and between the HFOV-B and HFOV-R groups $\left(\chi^{2}=34.381, p<0.001\right)$ were statistically significant. In contrast, the differences between the

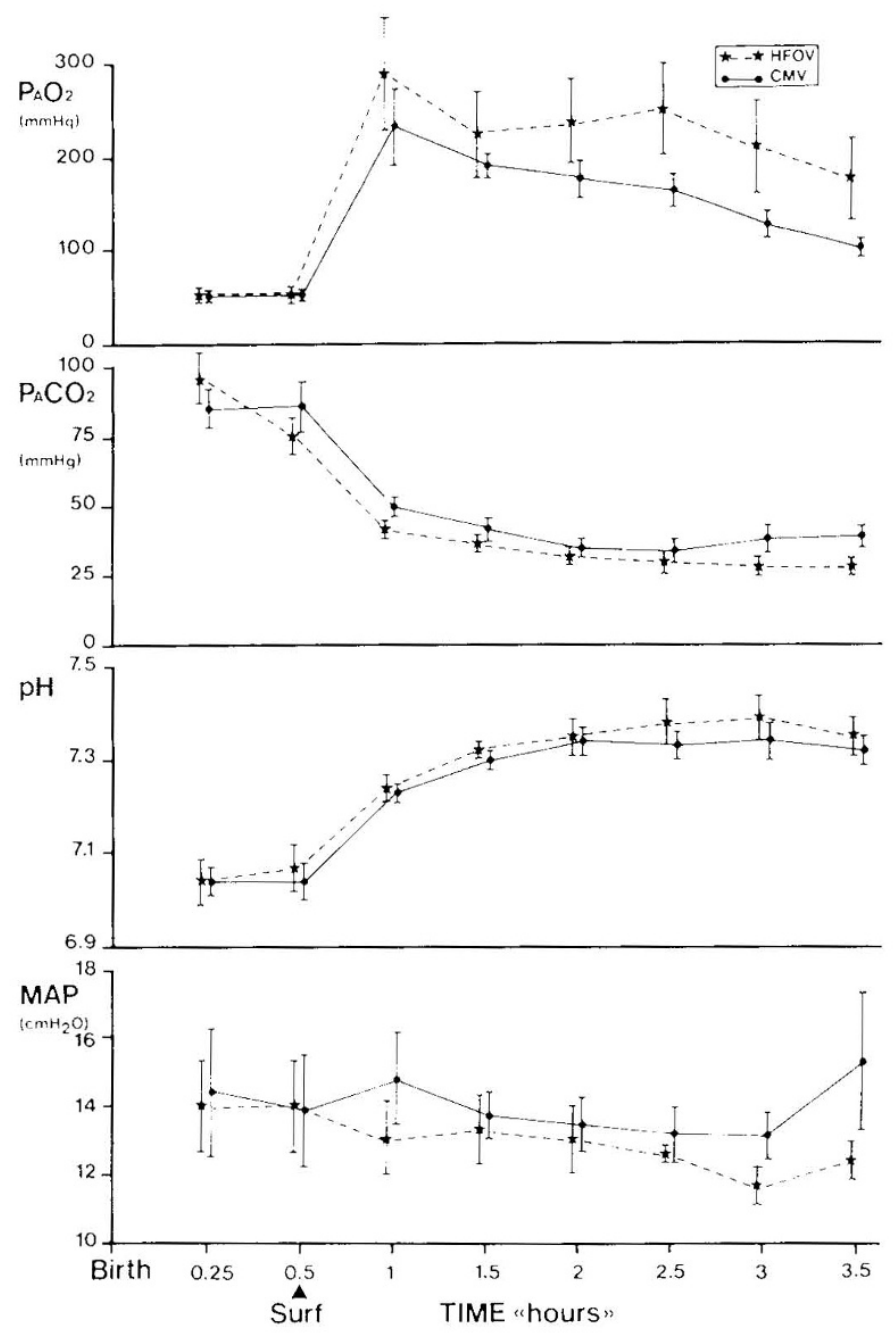

Fig. 2. Mean $( \pm S D)$ values of the $\mathrm{PaO}_{2}, \mathrm{PaCO}_{2}, \mathrm{pH}$, and $\mathrm{M} \wedge \mathrm{P}$ of the lambs treated with radiolabeled surfactant after $30 \mathrm{~min}$ of mechanical ventilation for RDS (groups (MV-R and HFOOV-R).

HFOV-R and CMV-R and between the HFOV-B and CMV-B groups were only minor. In the CMV-R group more radiolabeled surfactant was found in pieces from the left than from the right lung and more in the upper lobes of each lung than in the lower lobes (Table 1). Left to right lung and upper to lower lobe distribution was comparable for the other three groups of lambs except that the left upper lobes of the lambs in the HF()-B group received more radiolabeled surfactant than the left lower lobes $(p<0.005)$.

Morphometrics (Table 2) demonstrated significantly better expansion of the alveoli of lambs ventilated with HF() V than of those on CMV. This difference was irrespective of the timing of surfactant administration. Hyaline membranes, alveolar edema, and distension of the lymphatic vessels were more often seen in the CMV-R group than in any of the other three groups. Inadvertent PEEP changes were minimal $\left(<0.5 \mathrm{~cm} \mathrm{H}_{2} \mathrm{O}\right)$ in all lambs on HFOV.

\section{DISCUSSION}

Although mechanical ventilation has markedly improved outcome in premature infants with RDS. the use of high airway pressures and high oxygen concentrations has also led to the appearance of acute and chronic lung disease (14. 15). Highfrequency ventilation has been tried in animals and as a rescue mode for infants in whom lung barotrauma developed or in whom CMV failed because it can provide adequate gas exchange at lower airway pressures than CMV $(9,16,17)$. However, it 


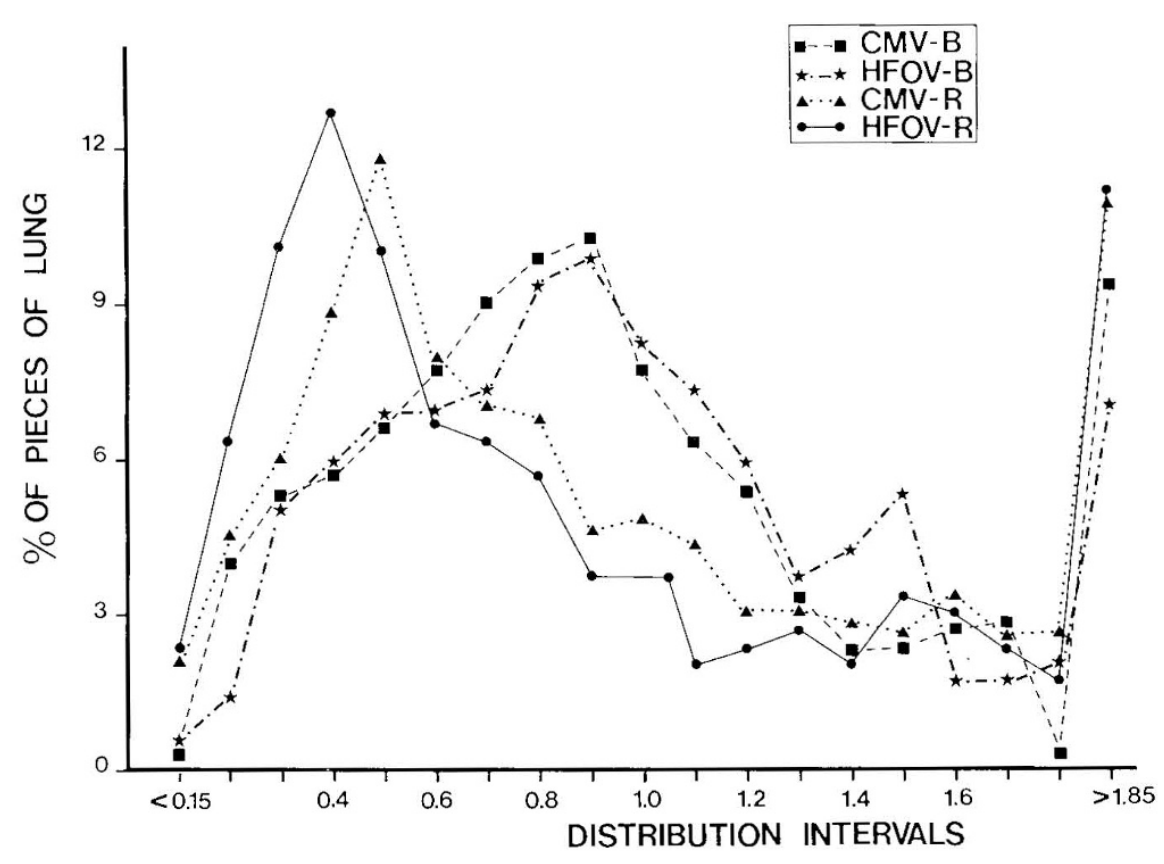

Fig. 3. Distribution of radioactive labeled surfactant in the four groups of lambs.

Table 1. Relative distribution of surfactant by lobes (mean $\pm S D$ )

\begin{tabular}{lllll}
\hline & CMV-B & HFO-B & CMV-R & HFO-R \\
\hline Left upper lobe & $0.86 \pm 0.51$ & $1.20 \pm 0.53^{*}$ & $1.44 \pm 1.01^{*}$ & $0.99 \pm 1.14$ \\
Left middle lobe & $0.93 \pm 0.79$ & $1.16 \pm 0.49$ & $1.03 \pm 0.60$ & $0.61 \pm 0.44$ \\
Left lower lobe & $1.03 \pm 0.77$ & $0.94 \pm 0.49$ & $1.12 \pm 0.61$ & $1.13 \pm 1.26$ \\
Right upper lobe & $1.19 \pm 1.16$ & $0.95 \pm 0.62$ & $0.95 \pm 0.60^{*}$ & $0.92 \pm 0.96$ \\
Right middle lobe & $0.98 \pm 0.69$ & $1.02 \pm 0.69$ & $0.79 \pm 0.47$ & $1.12 \pm 0.80$ \\
Right lower lobe & $0.92 \pm 0.58$ & $0.90 \pm 0.43$ & $0.72 \pm 0.64$ & $1.01 \pm 0.66$ \\
Total left lung & $0.95 \pm 0.65$ & $1.08 \pm 0.53$ & $1.24 \pm 0.82 \dagger$ & $1.00 \pm 1.13$ \\
Total right lung & $1.03 \pm 0.85$ & $0.96 \pm 0.59$ & $0.79 \pm 0.53$ & $1.02 \pm 0.81$ \\
\hline
\end{tabular}

* Upper lobes $>$ lower lobes $(p<0.05)$.

$\dagger$ Total left lung $>$ total right lung $(p<0.001)$.

Table 2. Alveolar surfaces (in $\mu m^{2}$ ) obtained by morphometrics

\begin{tabular}{lcc}
\multicolumn{4}{c}{ (mean \pm SEM) } \\
\multicolumn{1}{c}{ Groups } & Alveolar surface & $p$ \\
\hline CMV-B & $1401 \pm 25$ & \\
HFOV-B & $3215 \pm 46$ & $<0.001$ \\
CMV-R & $1985 \pm 35$ & \\
HFOV-R & $3443 \pm 56$ & $<0.001$ \\
CMV-B and CMV-R combined & $1643 \pm 21$ & $<0.001$ \\
HFOV-B and HFOV-R combined & $3318 \pm 42$ & \\
\hline
\end{tabular}

remains to be seen whether there is any clinical advantage to this form of mechanical ventilation. In this study, HFOV was delivered with a piston system at a frequency of $15 \mathrm{~Hz}$ and a VT of $2 \mathrm{ml} / \mathrm{kg}$. These settings have been shown to be effective in both clinical trials $(9,16,17)$ and animal experiments $(18,19)$. HFOV was superimposed on CMV in order to prevent atelectasis (9). As we had no data on the amount of background ventilation needed, a starting rate of $40 / \mathrm{min}$ at the described settings was chosen. The rate could be reduced to a $5-10$ breaths/min after confirmation of hyperoxia and normocapnia without detrimental effects.

At comparable $\mathrm{PaO}_{2} \mathrm{~S}$, MAPs during CMV were significantly lower in the lambs that received surfactant at birth than in those treated after the establishment of respiratory failure. This indicates that prophylaxis with surfactant leads to lower MAPs than rescue with surfactant followed by CMV. There was no clear difference in mean MAPs between the two HFOV groups, indi- cating that during HFOV the timing of surfactant instillation was not relevant. Calculation of the VI showed that MAPs during HFOV were significantly lower than in the CMV group rescued after birth with surfactant and equal to or higher than the CMV group treated with surfactant at birth. This positive aspect of HFOV has also been seen in studies in rabbits (8) and premature infants $(9,17)$.

The distribution of radiolabeled surfactant was independent of the type of ventilation used and clearly related to the timing of its administration. Instillation into the fluid-filled airways before the initiation of breathing at birth appeared to be the optimal time of surfactant administration. This confirms the findings from experiments in premature lambs (2) and rabbits (20). Except in the CMV-R group, we found no difference in left to right lung distribution of radiolabeled surfactant. There was a preference for distribution of exogenous surfactant to the upper lobes of both lungs in the CMV-R group and for the left lung in lambs of the HFO-B group. Preferred distribution of exogenous surfactant to the left lung and to the upper instead of the lower lobes was found by Jobe et al. (1) in premature lambs treated with surfactant after a period of mechanical ventilation, but not in lambs treated at birth. The absence of regional maldistribution of surfactant in the HFO-R group is in line with the morphometric findings in both HFOV groups.

The alveoli of both groups of lambs ventilated with HFOV were relatively better expanded than those of the CMV groups. This finding is inconsistent with the physiologic data. If alveolar size were larger one might argue that the "real" VI should also be higher insofar as size reflects volume, whereas we found that 
at comparable pressures, alveolar volume was greater. This was not, however, reflected in improved oxygenation as measured by the VI. If the increased alveolar size is a beneficial effect, why is it not reflected in improved oxygenation? Theoretically, the greater alveolar volume may be ascribed to gas trapping (21). The absence of inadvertent PEEP suggests that the effect we observed with HFOV may not be airtrapping but rather more uniform acration and modification of the "natural" course of RDS by prevention of airway injury, edema, and release of chemical mediators. We expected an independent effect of surfactant administration on alveolar volume as seen in premature rabbits treated with surfactant at birth and ventilated by HFOV (22). This feature did probably not emerge in our study due to surfactant treatment of all lambs, either at birth or after establishment of RIDS

We found surfactant treatment at birth to be the most efficient method of surfactant delivery and HFOV superimposed on CMV to lead to more uniform aeration. Since there were clear differences between the ventilation strategy we chose and that reported by others (using HFOV alone), this may account for the absence of more striking intergroup ventilator-associated differences. As HFOV combined with surfactant administration leads to more uniform aeration and less airway injury of the premature lung. this combination may be advantageous in treatment of severe RDS over either modality alone.

Acknowledgments. The authors thank Ton van den Bogaard. May Bost, Pieter Degraeuwe, Mieke Houdijk, Germa van de Kamp, Theo van der Nagel, and Mark Walther for technical assistance.

\section{REFHERENCIS}

1. Jobe A, Ikegami M, Jacobs H. Jones \$ 1984 Surfactant and pulmonary blood flow distributions following treatment of premature lambs with natural flow distributions following treatm
surfactant. J ( lin Invest 73:848-856

2. Jobe A. Ikegami M. (ilat/ T, Yoshida Y. Diakomanolis 1: Padbury J 1981 Duration and characteristics of treatment of premature lambs with natural surfactant J Clin Invest 67:370)-375

3. Enhorning (;. Shennan A. Possmayer I. Dunn M. Chen (P. Milligan J 1985 Prevention of neonatal respiratory distress syndrome by tracheal instillation of surfactant: a randomized clinical trial. Pediatrics $76: 145-153$

4. Smyth JA. Metcalfe II. Duffty P. Possmayer $\Vdash$, Bryan MH, Enhorning (; 1983 Hyaline membrane disease treated with bovine surfactant. Pediatries 71:913917
5. (hang HK 1984 Mechanisms of gas transport during sontilation by highfrequenes oscillation. J Apnl Phosiol $56.553-56.3$

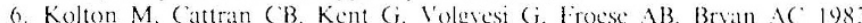
Oxygenation during high-frequency ventilation compared with consentional mechanical ventiation in (wo models of lung injury. Anesth Analg 61:3233.32

7. Hamilton PP Onaveni A Smyth JA Gillan Jl: (ut F Froese AB Bryan As 1983 Comparison of conventional and high-frequeney ventilation: oxvgenattion and lung pathology. J Appt Physiof 55:131-1.38

8. Blanco ( $\mathrm{F}$. Maertzdort $\mathrm{W} \mathrm{J}$. Walther $\mathrm{FJ} 1987$ lise of combined high-frequene oscillation and intermittent mandatory ventilation in rabbits with saline lavaged lungs. J Intensise (are Med 2:214-217

9. Boynton BR Mannino I.I Davis RF Kopotic RJ Fricderichsen (i 1)8 Combined high-frequency oscillatory ventilation and intermittent mandators ventilation in critically ill neonates. J Pediatr 105:297-302

10. Walther FJ. Blanco ( 1 . Houdijk M. Bevers 1 M 1985 Single versus repetitive doses of natural surfactant as treatment of respirators distress ssndrome in premature lambs. Pediatr Res 19:224-227

11. Jacobs $H$. Jobe A. Ikegami M (onawas D) 1983 The significance of reutilizittion of surfactant phosphatidylcholine. J Biol (hem $258: 41.59-4165$

12. Weibel ER 1963 Principles and methods for the morphometric study of the lung and other organs. Lab Invest 12:131-155

13. Cook PN. Batnitzky S. I.ee KR. Cook I.I. Fritz SL., Dwer S.I. (harlson I: 1981 thres-dimensional reconstruction from seriel sectuens for modical applications. Procedings of the th thawaii International (onference System Sciences 2:358-389

14. Reynolds EOP. Taghizadeh A 1974 Improved prognosis of infants mechani cally ventilated for hyaliene membrane disease. Arch I) is ( Child 49$), 5(0,5-515$

15. Heicher DA Kasting DS. Harrod JR 1981 Prospective clinical comparison of

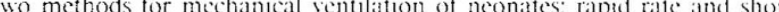
inspiratory time versus slow rate and long inspiratory lime. I Pediatr () S.() 57 inspirat

16. Marchak BE. Thompson WK. Dufty P. Migaki T. Bryan MH. Bryan AC Froese $A B 1981$ Treatment of RDS by high-frequency oscillator wentilation: a preliminary report. J Pediatr $99: 287-292$

17. Frantz ID Werthammer J Stark $A R \quad 1983$ High-frequency ventiation in premature infants with lung discase: adequate gas exchange at low tracheal pressure. Pediatrics $71: 483-488$

18. Bohn DJ. Miyasaka K. Marchak BI. Thompson WK. Froese AB. Bryan AC 1980 Ventilation by high-frequency oscillation. J Appl Phosiol 48:71()-716

19. Wright K I vrene RK Truog W'E Standacr 1A Murphy J Woodrum DI 1981 Ventilation by high-frequency oscillation in rabbits with oicic acid lung discase. J Appl Physiol 50:1056-1060

20. Vilsson R. Berggren P. Curstedt I. Grossmann (i. Renheim (i. Robertson B 1985 Surfactant treatment and entilation by high frequency oscillation in premature newborn rabbits: effect on survival, lung acration, and bronchiolar cpithelial lesions. Pediatr Res 19:143-147

21. Solimano A. Bryan C. Jobe A. Ikegami M. Jacobs H lys5 fffects of high frequency and conventional ventitation on the premature lamb lung. I Appl Physiol 59:1571-1577

22. Bancalari A, Gerhardt I, Bancalari IE. Suguibara (. Hehre I), Reifenberg I Goldherg RN 1987 (ias trapping with high-frequency ventilation: Jet versus oscillatory ventilation. J Pediatr 110:617-6222 